\title{
Second to fourth digit ratio: a predictor of adult penile length
}

\author{
In Ho Choi ${ }^{1}$, Khae Hawn Kim ${ }^{1}$, Han Jung ${ }^{1}$, Sang Jin Yoon ${ }^{1}$, Soo Woong Kim ${ }^{2}$ and Tae Beom Kim ${ }^{1}$
}

The second to fourth digit ratio (2D:4D) has been proposed as a putative biomarker for prenatal testosterone and covaries with the sensitivity of the androgen receptor (AR). Both prenatal testosterone and the AR play a central role in penile growth. In this study, we investigated the relationship between digit ratio and penile length. Korean men who were hospitalized for urological surgery at a single tertiary academic centre were examined in this study, and 144 men aged 20 years or older who gave informed consent were prospectively enrolled. Right-hand second- and fourth-digit lengths were measured by a single investigator prior to measurement of penile length. Under anaesthesia, flaccid and stretched penile lengths were measured by another investigator who did not measure nor have any the information regarding the digit lengths. Univariate and multivariate analysis using linear regression models showed that only height was a significant predictive factor for flaccid penile length (univariate analysis: $r=0.185, P=0.026$; multivariate analysis: $r=0.172, P=0.038$ ) and that only digit ratio was a significant predictive factor for stretched penile length (univariate analysis:

$r=-0.216, P=0.009$; multivariate analysis: $r=-0.201, P=0.024$; stretched penile length $=-9.201 \times$ digit ratio +20.577 ). Based on this evidence, we suggest that the digit ratio can predict adult penile size and that the effects of prenatal testosterone may in part explain the differences in adult penile length.

Asian Journal of Andrology (2011) 13, 710-714; doi:10.1038/aja.2011.75; published online 4 July 2011

Keywords: digit ratio; flaccid penile length; stretched penile length

\section{INTRODUCTION}

The ratio of second to fourth digit length (digit ratio, 2D:4D) is sexually dimorphic in humans (the mean digit ratio is lower in males than females $)^{1-5}$ and is thought to be fixed early in development. ${ }^{6-10}$ Across vertebrate species including humans, the Homeobox (Hox) a and $d$ genes regulate limb development, including fingers and toes, as well as development of the urogenital system, including testes, ovaries and penises. ${ }^{6,7,11,12}$ Manning et al. ${ }^{13}$ observed that the mean testis volume was significantly negatively correlated with the right digit ratio in azoospermic men. ${ }^{13}$ These observations have led to the suggestion that patterns of digit formation may be related to gonad function. ${ }^{1,11,14}$

A previous study reported that the digit ratio of the right hand was negatively correlated with the foetal testosterone/foetal estradiol ratio. ${ }^{15}$ As a result, a high level of foetal testosterone relative to foetal estradiol is associated with a low digit ratio. More convincing evidence regarding a link between prenatal testosterone and digit ratio comes from observations of digit ratios in girls with congenital adrenal hyperplasia ${ }^{4}$ and in genetic males with complete androgen insensitivity. ${ }^{16}$

A lack of association between digit ratio and circulating testosterone levels ${ }^{17}$ and the longitudinal stability of digit ratio ${ }^{18}$ has also been reported. These findings add to the evidence demonstrating that digit ratio is a suitable tool to study the effects of prenatal androgen. Furthermore, it has recently been suggested that the digit ratio of the right hand is related to the activity of the androgen receptor (AR). ${ }^{19}$

Like digit development, penile growth is influenced by prenatal testosterone. ${ }^{20-26}$ Androgens and a functioning androgen receptor are known to be necessary for normal development of the human penis. ${ }^{20,26-31}$ However, to date, there have been few studies that reveal why men who undergo normal puberty have different penile lengths.

Based on these evidences, we hypothesized that prenatal testosterone levels play a possible role in different penile lengths and considered the possibility that digit ratio might be related to penile length; therefore, we investigated the relationship between digit ratio and penile length.

\section{MATERIALS AND METHODS}

Korean men hospitalized for urological surgery at a single tertiary academic centre were examined in this study, and 144 men aged 20 years or older were prospectively enrolled. Institutional Review Board approvals were obtained and all patients gave informed consent. Men with hypospadia, urethral stricture, Peyronie's disease, penile cancer, or a history of endocrine disease, urethroplasty or other penile surgery (except for circumcision) that has a major influence on penile length were excluded.

All the patients' height, weight, and finger and penile lengths were measured. The second and fourth digit lengths of the right hand were measured by a single investigator prior to measurement of penile length. Using a digital Vernier calliper accurate to $0.01 \mathrm{~mm}$, digit lengths were measured directly on the ventral surfaces of the fingers, from the crease proximal to the palm at the base of each digit to the digit tip. ${ }^{1}$ To minimize measurement errors, mean values of two digit ratios that were calculated from duplicate measurements were used in

${ }^{1}$ Department of Urology, Gachon University Gil Hospital, Incheon, Korea and ${ }^{2}$ Department of Urology, Seoul National University College of Medicine, Seoul, Korea Correspondence: Dr TB Kim (uroclinic@naver.com)

Received; 18 February 2011; Revised 4 April 2011; Accepted: 28 April 2011; Published online: 4 July 2011 
the analysis. The intraclass correlation coefficient (ICC) of two repeated measures of digit ratio by a single investigator was 0.967 , which was similar to that of the study by Allaway et al. ${ }^{32}$ $\left(\mathrm{ICC}_{1}=0.873, \mathrm{ICC}_{2}=0.934, \mathrm{ICC}_{3}=0.969\right)$. This suggests that a direct measurement of digit ratio using a digital Vernier calliper has acceptable repeatability. ${ }^{33,34}$

Penile lengths were measured by another single investigator who did not perform measurements or have any information regarding the digit lengths. Flaccid and fully stretched penile lengths were measured under anaesthesia. A rigid ruler was used to avoid measurement error due to penile curvature as described by Son et al. ${ }^{35}$ In order to minimize the effect of temperature and touch on penile size, penile length measurements were taken immediately after the patient undressed. Measurements were taken, while patients were lying down and the legs were slightly abducted. The starting point was on the dorsal aspect of the penis at its base at the pubic-penile skin junction, pushing the prepubic fat pad against the pubic bone, as described by Wessells et al. ${ }^{36}$ and the tip of the penis was the other reference point. In order to reduce errors in measurement, two measurements were performed and their mean values were recorded.

Relationships between study variables were analysed using Pearson's linear correlation. To identify the independent predictive factors influencing penile length, univariate and multivariate analyses were performed using linear regression modelling. Analysis was performed using SPSS 12.0 (SPSS Inc., Chicago, IL, USA), and differences were considered statistically significant when $P$ values were less than 0.05 .

\section{RESULTS}

Patients' characteristics are summarized in Table 1. Table 2 describes the detailed types of urology patients who were included in the study. None of the patients who were included in the study have a disease that has a strong influence on penile length (Table 2 ).

Table 3 summarizes the relationships between penile length and other study variables. Flaccid penile length was correlated with stretched penile length ( $r=0.727, P=0.000)$ (Table 3$)$. In the univariate analysis using a linear regression model, height, body mass index (BMI) and digit ratio were associated with flaccid penile length. Among these three variables (height, BMI and digit ratio), only height was a significant predictive factor for flaccid penile length $(r=0.172$, $P=0.038)$ in the multivariate analysis using a linear regression model. Similarly, in the univariate analysis using a linear regression model, height, the fourth-digit length and digit ratio were associated with stretched penile length. Among these three variables (height, fourthdigit length and digit ratio), only digit ratio was a significant predictive

Table 1 Characteristics of the study population $(n=144)$

\begin{tabular}{lcc}
\hline & Mean \pm s.d. & Median (range) \\
\hline Age (years) & $57.3 \pm 16.5$ & $59.0(21.0-89.0)$ \\
Height (cm) & $168.1 \pm 6.7$ & $168.0(152.0-184.0)$ \\
Weight (kg) & $67.1 \pm 10.3$ & $67.0(45.0-100.0)$ \\
BMI $\left(\mathrm{kg} \mathrm{m}^{-2}\right.$ ) & $23.72 \pm 3.08$ & $23.53(15.19-33.41)$ \\
Second-digit length (cm) & $7.3 \pm 0.5$ & $7.2(6.2-8.6)$ \\
Fourth-digit length (cm) & $7.5 \pm 0.6$ & $7.4(6.2-9.1)$ \\
Digit ratio & $0.97 \pm 0.04$ & $0.97(0.88-1.12)$ \\
Flaccid penile length (cm) & $7.7 \pm 1.7$ & $7.8(4.0-12.0)$ \\
Stretched penile length (cm) & $11.7 \pm 1.9$ & $11.5(7.5-17.0)$ \\
Penile ratio & $1.54 \pm 0.25$ & $1.50(1.15-2.44)$ \\
\hline
\end{tabular}

Abbreviations: BMI, body mass index; digit ratio, second digit length/fourth digit length; penile ratio, stretched penile length/flaccid penile length.
Table 2 Types of urology patients included in the study $(n=144)$

\begin{tabular}{|c|c|c|c|}
\hline Site & Diagnosis & Operation name & No. \\
\hline \multirow[t]{5}{*}{ Kidney } & & & 21 \\
\hline & Renal cell carcinoma & Radical nephrectomy & 15 \\
\hline & Renal cell carcinoma & Partial nephrectomy & 1 \\
\hline & Non-function kidney & $\begin{array}{l}\text { LESS nephrectomy } \\
\text { (retroperitoneum) }\end{array}$ & 1 \\
\hline & Renal stone & Percutaneous nephrolithotomy & 4 \\
\hline \multirow[t]{5}{*}{ Ureter } & & & 15 \\
\hline & $\begin{array}{l}\text { Transitional cell } \\
\text { carcinoma }\end{array}$ & Nephroureterectomy & 5 \\
\hline & UPJ stricture & Acucise & 2 \\
\hline & Upper ureter stone & Lapa ureterolithotomy & 4 \\
\hline & Mid to lower ureter stone & Ureteroscopic stone removal & 4 \\
\hline \multirow[t]{6}{*}{ Bladder } & & & 45 \\
\hline & Bladder tumour & TURB & 39 \\
\hline & Bladder tumour & Radical cystectomy & 1 \\
\hline & Bladder stone & Cystolitholapaxy & 3 \\
\hline & Bladder neck stricture & Transurethral incision & 1 \\
\hline & Hematuria & Transurethral coagulation & 1 \\
\hline \multirow[t]{5}{*}{ Prostate } & & & 25 \\
\hline & Prostate cancer & Radical retropubic prostatectomy & 12 \\
\hline & $\begin{array}{c}\text { Benign prostate } \\
\text { hyperplasia }\end{array}$ & TURP & 11 \\
\hline & $\begin{array}{l}\text { Benign prostate } \\
\text { hyperplasia }\end{array}$ & Open prostatectomy & 1 \\
\hline & $\mathrm{R} / 0$ prostate cancer & Prostate biopsy (transperineal) & 1 \\
\hline \multirow[t]{12}{*}{ Scrotum } & & & 38 \\
\hline & Varicocele & Varicocelectomy & 13 \\
\hline & S/P vasectomy & Vaso-vasostomy & 4 \\
\hline & Male infertility & Epi-vasostomy & 1 \\
\hline & Hydrocele & Hydrocelectomy & 6 \\
\hline & Testicular tumour & Radical orchiectomy & 4 \\
\hline & Undescended testis & Orchiopexy & 2 \\
\hline & Epididymal cyst & Epididymal cyst excision & 3 \\
\hline & Epididymitis & Epididymectomy & 2 \\
\hline & Inguinal hernia & Herniorrhaphy & 1 \\
\hline & Laceration & Wound repair & 1 \\
\hline & Condyloma & Condyloma excision & 1 \\
\hline
\end{tabular}

Abbreviations: LESS, laparoendoscopic single-site; TURB, transurethral resection of bladder tumour; TURP, transurethral resection of prostate; UPJ, ureteropelvic junction.

factor for stretched penile length $(r=-0.201, P=0.024)$ in the multivariate analysis using a linear regression model (Table 3 ).

As shown in Figure 1, stretched penile length was found to be negatively associated with digit ratio. Penile ratio (stretched penile length/flaccid penile length) was negatively correlated with flaccid penile length $(r=-0.698, P=0.000)$; however, it was not correlated with stretched penile length $(r=-0.046, P=0.585)$ (Table 3).

\section{DISCUSSION}

Androgens and a functioning AR are known to be necessary for normal development of the human penis. ${ }^{20,26-31}$ Although several studies have demonstrated that postnatal androgen exposure is important for penis growth, ${ }^{23,25,37-39}$ penis formation and its capacity to grow are determined foetally by foetal androgen action. ${ }^{20-26}$ Foetal androgen levels in males are elevated between weeks 8 and 24 of gestation, with peak levels occurring between weeks 14 and $16 .{ }^{31}$ Activation of AR by prenatal testosterone also appears to contribute to the development of male internal genital structures and the differentiation of male external genitalia. ${ }^{31}$ 
Table 3 Relationships between penile length and other study variables

\begin{tabular}{|c|c|c|c|c|c|c|c|c|}
\hline \multirow[t]{3}{*}{ Variables } & \multicolumn{4}{|c|}{ Flaccid penile length } & \multicolumn{4}{|c|}{ Stretched penile length } \\
\hline & \multicolumn{2}{|c|}{ Univariate } & \multicolumn{2}{|c|}{ Multivariate } & \multicolumn{2}{|c|}{ Univariate } & \multicolumn{2}{|c|}{ Multivariate } \\
\hline & $r$ & $\mathrm{P}$ value & $r$ & $\mathrm{P}$ value & $r$ & $\mathrm{P}$ value & $r$ & $\mathrm{P}$ value \\
\hline Height & 0.185 & 0.026 & 0.172 & 0.038 & 0.142 & 0.088 & 0.117 & 0.192 \\
\hline Weight & -0.035 & 0.677 & & & 0.016 & 0.845 & & \\
\hline BMI & -0.147 & 0.079 & -0.138 & 0.095 & -0.064 & 0.449 & & \\
\hline Digit ratio & -0.155 & 0.064 & -0.122 & 0.141 & -0.216 & 0.009 & -0.201 & 0.024 \\
\hline Stretched penile length & 0.727 & 0.000 & & & & & & \\
\hline Penile ratio & -0.698 & 0.000 & & & -0.046 & 0.585 & & \\
\hline
\end{tabular}

Abbreviations: BMI, body mass index; digit ratio, second digit length/fourth digit length; penile ratio, stretched penile length/flaccid penile length.

Several studies observed that Homeoboxgenes (Hox a and $d$ ) control the development of digits as well as the differentiation of testes and ovaries. $^{6,7,11,12}$ This observation has led to the suggestion that patterns of digit formation may be related to the development of the penis and to gonad function. ${ }^{1,11,14}$

Recently, Lutchmaya et al. ${ }^{15}$ showed that the digit ratio of the right hand was negatively correlated with foetal testosterone/foetal estradiol ratio. ${ }^{15}$ This may mean that digit ratio is sensitive to the effects of relative foetal testosterone and foetal oestrogen concentrations and that a high concentration of testosterone leads to a low digit ratio and suggests high prenatal testicular activity. ${ }^{40}$

Furthermore, Manning et al. ${ }^{19}$ demonstrated that the digit ratio of the right hand is positively correlated with the number of CAG repeats in the $A R$ gene and suggested that the digit ratio of the right hand is related to the activity of AR. It has been well established that the length of the CAG repeats is negatively related to sensitivity to testosterone. ${ }^{41,42}$

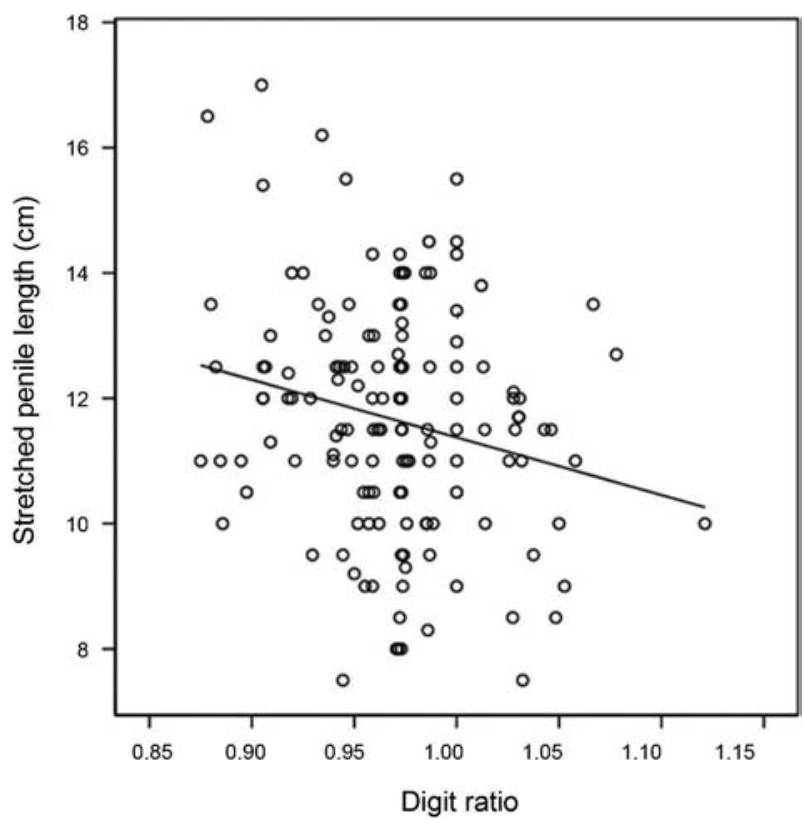

Figure 1 The relationship between digit ratio and stretched penile length. Stretched penile length was found to be negatively associated with digit ratio. $y=-9.201 x+20.577(r=-0.216, P=0.009)(y$ : stretched penile length; $x$ : digit ratio).
However, replication of this relationship between this $A R$ gene polymorphism and digit ratio was largely unsuccessful. ${ }^{43}$ Furthermore, although it seems that digit ratio is related to Hox $a$ and $d$ genes ${ }^{6,7,11,12}$ and $A R$ gene ${ }^{19}$ polymorphism, a recent study ${ }^{44}$ showed that digit ratio was not related to single-nucleotide polymorphisms in the $A R$ gene or in the Hox cluster of genes but was instead related to variation in the LIN28B gene, ${ }^{44}$ which has previously been associated with height ${ }^{45}$ and age at menarche in females. ${ }^{46-48}$ In contrast, another study observed simultaneous heterozygosities at three singlenucleotide polymorphisms in the HOX genes in a group of autistic individuals with low digit ratios, ${ }^{49}$ which indicates that the digit ratio may be related to the $H O X$ genes. Like these, the use of digit ratio as a non-invasive retrospective biomarker for prenatal androgen exposure is controversial; ${ }^{50}$ however, many researchers have adopted digit ratio as such. ${ }^{1,4,13,15-18,40,51-55}$

To date, it is well known that there are significant ethnic differences in digit ratio. In one study, the Oriental Han had the highest mean digit ratio, followed by the Caucasian Berbers and Uygurs, with the lowest mean ratios found in the Afro-Caribbean Jamaicans. ${ }^{56}$

Unlike digit ratio, studies have not found a relationship between penis size and race. ${ }^{57}$ However, there is considerable evidence that normal stretched penile length varied between ethnic groups. ${ }^{35,58-60}$ Among various ethnic groups, East Asians have slightly shorter stretched penile length when compared with other ethnic groups (Caucasian and African-American). ${ }^{35,58-60}$

Furthermore, to date, there have been few studies that reveal why men who undergo a normal puberty have different penile lengths. Interestingly, one study in Bulgaria observed that the average penis is bigger at birth and also at the end of sexual maturation in rural populations compared with urban populations. ${ }^{61}$ These data indicate that penile size at birth may be associated with penile size after puberty, and that prenatal androgen may have some influence on adult penile size.

Therefore, we hypothesized that the penile length differences between East Asians and other ethnicities may be the result of genetic differences and that the penile length differences between individuals in the same ethnic group may come from the differences of the milieu in utero, and we further considered the possibility that digit ratio might be related to penile length.

Among the many studies involving measurement of penile size, several reports have shown correlations between penile length and other somatometric parameters. To date, two studies have shown a correlation between height and penile length. ${ }^{62,63}$ Like those studies, the present study showed that flaccid penile length was positively 
correlated with height. Furthermore, the univariate and multivariate analyses showed that only height was a significant predictive factor for flaccid penile length (Table 3). However, in the present study, stretched penile length was not correlated with height but was negatively correlated with digit ratio (Table 3 ).

Two previous studies found correlations between the length of the second digit (index finger) and penile length. ${ }^{63,64}$ The present study does not support these findings; neither the length of the second digit nor the length of the fourth digit correlated with flaccid or stretched penile length (Table 3). However, the results of our univariate and multivariate analyses did show that stretched penile length correlated with digit ratio (Table 3 ), as men with a lower digit ratio tended to have a longer penile length (Figure 1). This means that it is not finger length but digit ratio that can predict adult penile length.

In the present study, penile ratio was negatively correlated with flaccid penile length (Table 3). These results indicate that elasticity of a small flaccid penis is higher than that of a large flaccid penis. This supports assertions by Masters and Johnson ${ }^{65}$ that a longer flaccid penis is not necessarily longer in erection than a shorter flaccid penis.

In the present study, we measured only the fingers of the right hand because there are numerous reports that differences between the sexes in digit ratio are greater on the right hand than on the left, and there are suggestions that the right hand may be more sensitive to the influence of testosterone. ${ }^{1,4,15,40,54,55}$

Several studies have suggested that males with a low digit ratio may be more likely to suppress signs of pain or discomfort, which could lead to the tendency to measure a longer stretched penis length in this group (low digit ratio) compared to the high-digit-ratio group. ${ }^{51-53}$ However, in the present study, penile length was measured under anaesthesia, avoiding pain or discomfort when the penis was fully stretched. Therefore, penile length measurement in our study was not influenced by pain perception.

It is also possible that the elasticity of soft tissues is influenced by prenatal testosterone and that age differences may explain some variation in penile length because penile extensibility decreases with age owing to the loss of elasticity of the tunica albuginea. ${ }^{66,67}$ However, in our data, there was no relationship between age and penile length (flaccid penile length: $r=0.066, P=0.430$; stretched penile length: $r=0.051, P=0.542$ ) (Table 3). Therefore, penile length may not be influenced by penile extensibility that decreases with age as a result of loss of elasticity of the tunica albuginea. These findings are similar to the results of Wessells et al. ${ }^{36}$

One limitation of our study is that it is not based on a normal population; rather, participants were recruited from among patients who were hospitalized for urological surgery at a single tertiary academic centre. Nevertheless, we assert that our results present sufficient evidence that a relationship exists between digit ratio and adult penile length, as we excluded patients with conditions known to have a strong influence on penile length.

Another limitation of this study is that we measured stretched penile length, not erectile penile length. However, many studies have reported a strong correlation between stretched penile length and erectile penile length and shown that stretched penile length provides a reliable estimate of the potential maximal elongation during erection. ${ }^{36,64,68-71}$ Therefore, the technique applied here for stretched penile length measurement is highly recommended for accurate prediction of erect penile length. ${ }^{69}$

During the foetal period, high concentrations of testosterone lead to high testicular activity, resulting in a lower digit ratio. In the present study, patients with a lower digit ratio tended to have a longer stretched penile length. Stretched penile length was negatively associated with digit ratio. Based on this evidence, we suggest that digit ratio can predict adult penile size and that the effects of prenatal testosterone may in part explain the differences in adult penile length.

\section{AUTHOR CONTRIBUTIONS}

IHC designed the study and acquired the data; KHK performed statistical analysis and helped to draft the manuscript; $\mathrm{HJ}$ acquired the data; SJY interpreted the data; SWK critically revised the manuscript for important intellectual content; TBK critically revised the manuscript for important intellectual content and helped to draft the manuscript.

\section{COMPETING FINANCIAL INTERESTS}

The authors have no financial or any other conflict of interest to declare regarding the contents of this article.

1 Manning JT, Scutt D, Wilson J, Lewis-Jones DI. The ratio of 2 nd to 4 th digit length: a predictor of sperm numbers and concentrations of testosterone, luteinizing hormone and oestrogen. Hum Reprod 1998; 13: 3000-4.

2 Peters M, Mackenzie K, Bryden P. Finger length and distal finger extent patterns in humans. Am J Phys Anthropol 2002; 117: 209-17.

3 Phelps VR. Relative index finger length as a sex-influenced trait in man. Am J Hum Genet 1952; 4: 72-89.

4 Hönekopp J, Watson S. Meta-analysis of digit ratio 2D:4D shows greater sex difference in the right hand. Am J Hum Biol 2010; 22: 619-30.

5 Manning JT. Digit Ratio: A Pointer to Fertility, Behaviour and Health. New Brunswick, NJ: Rutgers University Press; 2002.

6 Kondo T, Zakany J, Innis JW, Duboule D. Of fingers, toes and penises. Nature 1997, 390: 29.

7 Mortlock DP, Innis JW. Mutation of HOXA13 in hand-foot-genital syndrome. Nat Genet 1997; 15: 179-80.

8 Garn SM, Burdi AR, Babler WJ, Stinson S. Early prenatal attainment of adult metacarpal-phalangeal rankings and proportions. Am J Phys Anthropol 1975; 43: 327-32.

9 Malas MA, Dogan S, Evcil EH, Desdicioglu K. Fetal development of the hand, digits and digit ratio (2D:4D). Early Hum Dev 2006; 82: 469-75.

10 Galis F, Ten Broek CM, van Dongen S, Wijnaendts LC. Sexual dimorphism in the prenatal digit ratio (2D:4D). Arch Sex Behav 2010; 39: 57-62.

11 Voracek M, Manning JT. Length of fingers and penis are related through fetal Hoxgene expression. Urology 2003; 62: 201.

12 Zákány J, Formental-Ramian C, Warot X, Duboule D. Regulation of the number and size of the digits by posterior Hox genes: a dose-dependent mechanism with potential evolutionary implications. Proc Natl Acad Sci USA 1997; 94: 13695-700.

13 Manning JT, Wood S, Vang E, Walton J, Bundred PE et al. Second to fourth digit ratio (2D:4D) and testosterone in men. Asian J Androl 2004; 6: 211-5.

14 Robinson SJ, Manning JT. The ratio of 2 nd to 4 th digit length and male homosexuality. Evol Hum Behav 2000; 21: 333-45

15 Lutchmaya S, Baron-Cohen S, Raggatt P, Knickmeyer R, Manning JT. 2nd to 4th digit ratios, fetal testosterone and estradiol. Early Hum Dev 2004; 77: 23-8.

16 Berenbaum SA, Bryk KK, Nowak N, Quigley CA, Moffat S. Fingers as a marker of prenatal androgen exposure. Endocrinology 2009; 150: 5119-24.

17 Hönekopp J, Bartholdt L, Beier L, Liebert A. Second to fourth digit length ratio (2D:4D) and adult sex hormone levels: new data and a meta-analytic review. Psychoneuroendocrinology 2007; 32: 313-21.

18 Trivers R, Manning J, Jacobson A. A longitudinal study of digit ratio (2D:4D) and other finger ratios in Jamaican children. Horm Behav 2006; 49: 150-6.

19 Manning JT, Bundred PE, Newton DJ, Flanagan BF. The second to fourth digit ratio and variation in the androgen receptor gene. Evol Hum Behav 2003; 24: 399-405.

20 Baskin LS, Sutherland RS, DiSandro MJ, Hayward SW, Lipschutz J et al. The effect of testosterone on androgen receptors and human penile growth. J Urol 1997; 158: 1113-8.

21 Boas M, Boisen KA, Virtanen HE, Kaleva M, Suomi AM et al. Postnatal penile length and growth rate correlate to serum testosterone levels: a longitudinal study of 1962 normal boys. Eur J Endocrinol 2006; 154: 125-9.

22 Camurdan AD, Oz MO, IIhan MN, Camurdan OM, Sahin F et al. Current stretched penile length: cross-sectional study of 1040 healthy Turkish children aged 0 to 5 years. Urology 2007; 70: 572-5.

23 Husmann DA. Micropenis: an animal model and its human correlates. Adv Exp Med Biol 2002; 511: 41-56.

24 Welsh M, Saunders PT, Fisken M, Scott HM, Hutchison GR et al. Identification in rats of a programming window for reproductive tract masculinisation, disruption of which leads to hypospadias and cryptorchidism. J Clin Invest 2008; 118: 1479-90.

25 Welsh M, MacLeod DJ, Walker M, Smith LB, Sharpe RM. Critical androgen-sensitive periods of rat penis and clitoris development. Int J Androl 2010; 33: e144-52. 
26 Vogt K. Microphallus. Emedicine from WebMD. http://www.emedicine.com/PED/ topic1448.htm (accessed 12 November 2007).

27 Conte F, Grumbach M. Pathogenesis, classification, diagnosis and treatment of anomalies of sex. In: DeGroot LJ, editors. Endocrinology. 3rd ed. Philadelphia, PA: W. B. Saunders Co; 1995. pp618-70.

28 Quigley CA, de Bellis A, Marschke KB, El-Awady MK, Wilson EM et al. Androgen receptor defects: historical, clinical, and molecular perspectives. Endocr Rev 1995; 16: 271-321.

29 Hinman FJ. Penis and male urethra. In: UroSurgical Anatomy. Philadelphia, PA: W. B. Saunders Co; 1993. p418.

30 George F, Wilson J. Sex determination and differentiation. In: Knobil E, Neill J, editors. The Physiology of Reproduction. New York: Raven; 1994. pp114-60.

31 Byne W. Developmental endocrine influences on gender identity: implications for management of disorders of sex development. Mt Sinai J Med 2006; 73: 950-9.

32 Allaway HC, Bloski TG, Pierson RA, Lujan ME. Digit ratios (2D:4D) determined by computer-assisted analysis are more reliable than those using physical measurements, photocopies, and printed scans. Am J Hum Biol 2009; 21 : 365-70.

33 Scutt D, Manning JT. Symmetry and ovulation in women. Hum Reprod 1996; 11 : 2477-80.

34 Manning JT. Fluctuating asymmetry and bodyweight in men and women: implications for sexual selection. Ethol Sociobiol 1995; 16: 145-53.

35 Son H, Lee H, Huh JS, Kim SW, Paick JS. Studies on self-esteem of penile size in young Korean military men. Asian J Androl 2003; 5: 185-9.

36 Wessells H, Lue TF, McAninch JW. Penile length in the flaccid and erect states; guidelines for penile augmentation. J Urol 1996; 156: 995-7.

37 Herman RA, Jones B, Mann DR, Wallen K. Timing of prenatal androgen exposure: anatomical and endocrine effects on juvenile male and female rhesus monkeys. Horm Behav 2000; 38: 52-66.

38 Prahalada S, Tarantal AF, Harris GS, Ellsworth KP, Clarke AP et al. Effects of finasteride, a type 2 5-alpha reductase inhibitor, on fetal development in the rhesus monkey (Macaca mulatta). Teratology 1997; 55: 119-31.

39 Macleod DJ, Sharpe RM, Welsh M, Fisken M, Scott HM et al. Androgen action in the masculinization programming window and development of male reproductive organs. Int J Androl 2010; 33: 279-87.

40 Williams TJ, Pepitone ME, Christensen SE, Cooke BM, Huberman AD et al. Fingerlength ratios and sexual orientation. Nature 2000; 404: 455-6.

41 Chamberlain NL, Driver ED, Miesfeld RL. The length and location of CAG trinucleotide repeats in the androgen receptor $\mathrm{N}$-terminal domain affect transactivation function. Nucleic Acids Res 1994; 15: 3181-6.

42 Kazemi-Esfarjani P, Trifiro MA, Pinski L. Evidence for a repressive function of the long polyglutamine tract in the human androgen receptor: possible pathogenic relevance for the (CAG) $)_{n}$-expanded neuropathies. Human Mol Genet 1995; 4: 523-7.

43 Hurd PL, Vaillancourt KL, Dinsdale NL. Aggression, digit ratio and variation in androgen receptor and monoamine oxidase a genes in men. Behav Genet; e-pub ahead of print 22 October 2010; doi: 10.1007/s10519-010-9404-7.

44 Medland SE, Zayats T, Glaser B, Nyholt DR, Gordon SD et al. A variant in LIN28B is associated with 2D:4D finger-length ratio, a putative retrospective biomarker of prenatal testosterone exposure. Am J Hum Genet 2010; 86: 519-25.

45 Lettre G, Jackson AU, Gieger C, Schumacher FR, Berndt SI et al. Identification of ten loci associated with height highlights new biological pathways in human growth. Nat Genet 2008; 40: 584-91

46 Ong KK, Elks CE, Li S, Zhao JH, Luan J et al. Genetic variation in LIN28B is associated with the timing of puberty. Nat Genet 2009; 41: 729-33.
47 Sulem P, Gudbjartsson DF, Rafnar T, Holm H, Olafsdottir EJ et al. Genome-wide association study identifies sequence variants on $6 \mathrm{q} 21$ associated with age at menarche. Nat Genet 2009; 41: 734-8.

48 He C, Kraft P, Chen C, Buring JE, Pare G et al. Genome-wide association studies identify loci associated with age at menarche and age at natural menopause. Nat Genet 2009; 41: 724-8.

49 Sugie Y, Sugie H, Fukuda T, Osawa J. Study of HOXD genes in autism particularly regarding the ratio of second to fourth digit length. Brain Dev 2010; 32: 356-61.

$50 \mathrm{McIntyre} \mathrm{MH}$. The use of digit ratios as markers for perinatal androgen action. Reprod Biol Endocrinol 2006; 4: 10

51 Schwerdtfeger A, Heer J. Second to fourth digit ratio (2D:4D) of the right hand is associated with nociception and augmenting-reducing. Pers Indiv Diff 2008; 45: 493-7.

52 Keogh E, Mounce C, Brosnan M. Can a sexually dimorphic index of prenatal hormonal exposure be used to examine cold pressor pain perception in men and women? Eur J Pain 2007: 11: 231-6.

53 Yamamotova A, Benkova M, Pechova K, Rokyta R. Can second to fourth digit ratio (2D:4D) predict sensitivity to pain? Act Nerv Super Rediviva 2009; 51: 159-62.

54 Coates JM, Gurnell M, Rustichini A. Second-to-fourth digit ratio predicts success among high-frequency financial traders. Proc Natl Acad Sci USA 2009; 106: 623-8.

55 Manning JT, Churchill AJ, Peters M. The effects of sex, ethnicity, and sexual orientation on self-measured digit ratio (2D:4D). Arch Sex Behav 2007; 36: 223-33.

56 Manning JT, Stewart A, Bundred PE, Trivers RL. Sex and ethnic differences in 2nd to 4th digit ratio of children. Early Hum Dev 2004; 80: 161-8.

57 Adams MV. The Multicultural Imagination: Race, Color, and the Unconscious. London: Routledge; 1996. p164.

58 Wylie KR, Eardley I. Penile size and the 'small penis syndrome'. BJU Int 2007; 99: 1449-55.

59 Wang $\mathrm{CH}$, Lin WD, Bau DT, Tsai CH, Liu DC et al. Penile length of normal boys in Taiwan. Acta Paediatr Taiwan 2006; 47: 293-6.

60 Edward R. Definitive Penis Size Survey. 6th ed. 2002. http://www.sizesurvey.com

61 Tomova A, Deepinder F, Robeva R, Lalabonova H, Kumanov P et al. Growth and development of male external genitalia: a cross-sectional study of 6200 males aged 0 to 19 years. Arch Pediatr Adolesc Med 2010; 164: 1152-7.

62 Ponchietti R, Mondaini N, Bonafe M, Di Loro F, Biscioni S et al. Penile length and circumference: a study on 3,300 young Italian males. Eur Urol 2001; 39: 183-6.

63 Mehraban D, Salehi M, Zayeri F. Penile size and somatometric parameters among Iranian normal adult men. Int J Impot Res 2007; 19: 303-9.

64 Spyropoulos E, Borousas D, Mavrikos S, Dellis A, Bourounis M et al. Size of external genital organs and somatometric parameters among physically normal men younger than 40 years old. Urology 2002; 60: 485-9.

65 Masters WH, Johnson VE. Human Sexual Response. 1st ed. Boston, MA: Little Brown and Co.; 1966

66 Bondil P, Costa P, Daures JP, Louis JF, Navratil H. Clinical study of the longitudinal deformation of the flaccid penis and of its variations with aging. Eur Urol 1992; 21: 284-6.

67 Moreira de Goes P, Wespes E, Schulman C. Penile extensibility: to what is it related? J Urol 1992; 148: 1432-4.

68 Schonfeld WA, Beebe GW. Normal growth and variation in the male genitalia from birth to maturity. J Urol 1942; 48: 759-77.

69 Sengezer M, Ozturk S, Deveci M. Accurate method for determining functional penile length in Turkish young men. Ann Plast Surg 2002; 48: 381-5.

70 Mondaini N, Ponchietti R, Gontero P, Muir GH, Natali A et al. Penile length is normal in most men seeking penile lengthening procedures. Int J Impot Res 2002; 14: 283-6.

71 Chen J, Gefen A, Greenstein A, Matzkin H, Elad D. Predicting penile size during erection. Int J Impot Res 2000; 12: 328-33. 